\title{
Corpo, Lazer e Natureza: uma reflexão sobre os cruzeiros marítimos
}

\section{Body, Leisure and Nature: a relfexion over cruising}

Telma Medeiros Brito ${ }^{1}$

Heloisa Turini Bruhns ${ }^{2}$

\section{Resumo}

A discussão sobre os cruzeiros marítimos enquanto opção contemporânea de viagem de lazer é relativamente recente e tem ganhado cada vez mais interesse, não só do mercado turístico em geral, mas também do meio acadêmico. Este estudo pretende ampliar esta discussão, refletindo sobre o lazer oferecido a bordo dos navios e sua relação com a lógica do tempo, o contato com a natureza e o significado do corpo e sensações que esta prática proporciona, temas estes envolvidos diretamente com a prática dos cruzeiros marítimos.

Palavras-chave: cruzeiros marítimos; turismo; lazer; lazer em cruzeiros marítimos.

\begin{abstract}
The discussion about cruising as an actual option of leisure travel is recent and it has achieved more interest, not only from the trade, but also from the academics. This study aims to enlarge this discussion, with a reflection over the leisure activities offered on board and its relation to the time logical, the nature contact and the body meaning and feelings that this practice causes, themes directly envolved with the cruising experience.
\end{abstract}

Keywords: cruising; tourism; leisure; leisure on board cruise ships.

\section{Lazer e prazer}

O mundo contemporâneo criou diversas atividades de lazer para que o homem empregue o seu denominado tempo "livre". Muitas envolvem altos recursos financeiros para que sejam realizadas. Uma das atividades de lazer criada na modernidade para que o homem usufrua desse tempo "livre” é a viagem e uma das opções de viagem de lazer procurada nos dias atuais é aquela realizada a bordo dos navios de cruzeiros.

O fenômeno lazer vem se apresentando como justificativa para muitas práticas e opções de vida. A sociedade vem se urbanizando cada vez mais em conseqüência do avanço industrial e tecnológico. Mudam-se as concepções, os conceitos e os comportamentos, muitas vezes dificultando a reflexão e a crítica nesse emaranhado e nessa roda viva, onde o ritmo de vida é

\footnotetext{
${ }^{1}$ Bacharel em Turismo pela Faculdade Ibero-Americana, especialista em Planejamento e Marketing Turístico pelo Senac e mestranda da Faculdade de Educação Física (ênfase em Sociedade e Lazer) da Unicamp. Docente no curso de Turismo do Unibero. E-mail: telmabri@terra.com.br

${ }^{2}$ Professora Titular Unicamp do Departamento de Estudos do Lazer e Pesquisadora do CNPq. E-mail: luabola@uol.com.br
} 
levado ao extremo. Nesse panorama, torna-se fácil colaborarmos com comportamentos e realizações que às vezes repudiamos.

Uma rápida observação nos mostra que o sistema em que estamos inseridos, tem utilizado esse espaço para tentar incrementar o consumismo fácil e supérfluo, diversificando a produção de bens utilizados nessas horas vagas. Porém, como bem discute De Grazia citado em Bruhns (2002), alguém sozinho pode gozar o lazer e mercadoria nenhuma fará falta; basta realizar um passeio ao ar livre.

Desta forma, o lazer não estaria atrelado à abundância ou luxo, mas a um estado de serenidade e tranqüilidade. Nesse sentido, o tempo não realiza o lazer o qual não se concretizará sob o controle do tempo.

Porém, vivemos dentro de uma lógica onde o tempo significa dinheiro e não podemos perder tempo (o qual deve ser economizado, investido, conquistado e contado). Devemos sempre estar "fazendo coisas” para justificar nossa produtividade e naturalmente isso gera ansiedade e desconforto, pois a preocupação está sempre no “fazer o seguinte”.

O homem contemporâneo compra seus prazeres com o dinheiro de seu trabalho na ilusão de vivenciá-los em seu tempo "livre”. O lazer torna-se algo quantificável e compulsório, ou seja, um repouso imposto pela racionalização do tempo, onde o prazer também passa a ser fundamental e obrigatório.

Devemos estar atentos sobre a questão do prazer, bastante almejado, porém nem sempre alcançado, pois os dissabores são múltiplos, no que se refere ao quadro social de insegurança instaurado no cotidiano, proveniente desde a questão do desemprego, violência (física e moral, relacionada à miséria) passando pela grande carga de informações gerando angústia pela não-capacidade de sua absorção, como a intensa competitividade gerada nesse processo. A necessidade de estarmos sempre "ligados" nos conduz a experimentarmos frações de prazer nem sempre completados. Permanecemos sonhando com ilhas paradisíacas...

Nesse quadro, o cotidiano serve como espaço para o envio de mensagens de encantamento, destinadas a capturar o desejo e a fantasia, através de promessas de personalização. Sedução torna-se sinônimo de atração.

Baudrillard (1992), vem nos auxiliar, esclarecendo como uma "sedução fria”, revisada e corrigida pela ideologia do desejo, governa a esfera da informação e da comunicação, 
denominada sedução/simulacro (psicológica e operacional, da estratégia dos jogos ${ }^{3}$, da era da fascinação), oposta à sedução-desafio (esfera do encantamento), dual e antagônica, da aposta máxima, da sedução mítica, apenas um processo imoral, frívolo, superficial, supérfluo, da ordem do universo simbólico (dos signos e das aparências, “voltado aos prazeres e à fruição dos corpos inúteis”).

Ainda segundo Baudrillard,

$a$ sedução na forma atual, perdeu o aleatório, o suspense, o sortilégio, para se revestir da forma de uma obscenidade leve e indiferenciada”. Cúmplice de um mercado, a sedução serve à circulação das trocas, não restando o "encantamento de uma estrutura labiríntica em que o ser se perde.(1992, p.205)

Nesse processo de sedução/simulacro, numa espetacularização do cotidiano, composto pelo “incrível”, “sensacional”, “fantástico”, imagens são criadas, insuflando desejos e criando carências, revestindo o real com uma aparência desejável.

É desenvolvido um consumo, não por necessidade, mas por ansiedade, suscitando a dúvida se é possível não vincular à estratégia do consumo a estratégia da sobrevivência, uma vez que a identidade social do indivíduo se afirma na esfera do consumo, enquanto no ar paira a incerteza quanto ao futuro e a ameaça da exclusão.

Porém, com Santos (2000) acreditamos sobre o jogo não ter acabado - ele nunca acaba prossegue em outro plano, em outro paradigma, em outro espaço-tempo. Assim sendo, mais eficiente do que se deixar abalar com essas regras da sociedade de controle, seria descobrir como “no jogo infinito, elas podem ser desreguladas”.

Assim podemos nos aproximar na crença da possibilidade do prazer, conforme Maffesoli (1998), constituir-se na expressão de um desejo de vida irreprimível, insistindo pelo seu espaço social, representado pelas pequenas conquistas do cotidiano.

Mais do que a presença de um poder presencia-se uma "potência da socialidade", emprestando o termo do autor (MAFFESOLI, 1998), para o qual esta pode se manifestar, subvertendo a ordem estabelecida na forma do silêncio, da astúcia, da luta, da passividade, do humor ou do escárnio, resistindo à imposição do poder. Portanto, o insignificante faz sentido, uma vez enfrentando instituições macroscópicas e dominantes. Revela-se uma dimensão

\footnotetext{
${ }^{3}$ Essa estratégia de jogo envolve o funcionamento das redes, seu modo de investimento e manipulação, regulando a generalidade de nossas trocas. Segundo Baudrillard (1992:179), define-se "pela possibilidade de prever todos os golpes do adversário e de dissuadí-los antecipadamente” , tornando impossível qualquer aposta. É ela quem confere seu caráter lúdico a um mundo paradoxalmente sem apostas.
} 
crítica no movimento contemporâneo, não negando aqui suas ambigüidades e, portanto, não dispensando a necessidade de discernimento e superação.

Não podemos deixar de considerar essa ambigüidade em relação ao prazer presente na busca do cruzeiro marítimo enquanto opção de lazer, onde o trânsito entre as possibilidades de regulamento e desregulamento fazem-se presentes, num movimento envolvendo contradições, afirmações e negações de conceitos, idéias e comportamentos.

\section{Viagens, cruzeiros e paisagens}

Viajar é uma das formas de lazer que a sociedade contemporânea encontrou para empregar o denominado tempo "livre" e o dinheiro, fruto de seu trabalho. Viajar pode alargar horizontes, aproximar os povos socialmente, aumentando a comunicação entre as nações, envolvendo o processo de aculturação. As viagens reúnem o deslocamento e afastamento do local de residência por um determinado tempo, que segundo Bruhns (2002), aproximam-se dos ritos de passagem. Citando Ortiz, a autora aponta um importante processo das viagens - aquele que torna os viajantes um intermediário entre sítios e culturas distantes, pois colocam em comunicação lugares separados pela distância e pelos hábitos culturais (apud BRUHNS, 2002).

Os cruzeiros marítimos, enquanto opção de viagem de lazer, têm se tornado bastante populares no Brasil (se não efetivamente através da realização, através das propagandas bastante difusas, insuflando desejos e imaginação). Algumas das razões de escolha para este tipo de viagem poderiam ser as diversas atividades de lazer e entretenimento oferecidas a bordo dos navios de cruzeiro, a oportunidade de contato com a natureza (céu, mar e sol), a visão de diferentes paisagens e ainda, o contato com culturas diversas.

Pesquisa recente (RABAHY e KADOTA, 2006) apontou que o principal motivo para a realização de uma viagem marítima no Brasil era "vivenciar a experiência de viajar de navio". O prazer da viagem marítima de lazer é ainda uma incógnita para muitos. A busca pelo novo, pelo diferente, pelo prazer acessível a poucos, pelo ambiente de glamour, pelo inusitado são fatores que podem influenciar na escolha desta experiência.

Uma viagem por mar pode proporcionar uma sensação de liberdade, conforto e integração com a natureza. O homem se descobre num estado diferente do seu cotidiano, no estado de observador da dimensão e da força do mar, cuja cor, tonalidades e sons são diferentes daquelas observadas da praia, à beira mar. As cores do céu também se modificam e oferecem 
verdadeiros espetáculos, tanto ao amanhecer quanto ao anoitecer. Todos estes elementos colaboram para criar um imaginário em torno dos cruzeiros.

Um cruzeiro marítimo talvez seja a opção de viagem de lazer que apresente a maior simbologia para os indivíduos na atualidade. Inegavelmente, o mar sempre exerceu um fascínio sobre as pessoas, seja pelos seus mistérios, seja pelas narrativas poéticas. Sua imensidão e sua força provocam medo e ao mesmo tempo, respeito, excitação e prazer. Suas lendas contadas de geração em geração e seus deuses, como Netuno, sempre foram lembrados na mitologia. O desejo de cruzar os oceanos em busca do desconhecido levou o homem para o mar. A necessidade da descoberta de novas terras ou mesmo a aventura foi maior que o próprio terror deste gigante desconhecido. A imagem do mar-oceano está ligada à imagem da navegação e à da travessia (DIEGUES, 1998, p.25)

As imagens e o prazer visual proporcionados por uma viagem marítima são percebidos de forma e intensidade diferentes por cada viajante. De maneira geral, todos são estimulados, em diferentes graus, a liberar a imaginação - seja por meio das propagandas ou pelo simples desejo de viver a experiência. Nos aproximando de Bruhns (2002) sobre as viagens à natureza, podemos dizer que os cruzeiros são uma aventura imaginada, pois trata-se de um acontecimento muito distante da vida cotidiana. O ambiente de um navio, que até os dias atuais gera um certo fascínio e aproximação com certo glamour, combinado com a natureza, cria sensações muitas vezes inexplicáveis para os turistas. Afirmações como: "é um sonho de viagem”, "é um luxo", "é maravilhoso" são comuns de se escutar a bordo dos navios e mesmo em vídeos promocionais divulgados pelas companhias marítimas.

As viagens por oceanos e mares estimulam a imaginação do viajante, não só com relação à simbologia do mar, mas também com relação à própria experiência de navegar. Segundo Bachelard (1997, p.18), a “imaginação não é, como sugere a etimologia, a faculdade de formar imagens da realidade: é a faculdade de formar imagens que ultrapassam a realidade, que cantam a realidade”.

Um dos componentes importantes nos cruzeiros marítimos é a paisagem. Embora uma das principais motivações que levam um viajante a optar pelas viagens marítimas seja o desejo de viver a experiência, além da infra-estrutura e as opções de lazer que os navios oferecem atualmente, a paisagem também pode estar inserida neste rol. Os diferentes destinos oferecidos podem tornar-se um ponto de referência expressivo para a escolha da viagem. 
A experiência de uma viagem a bordo de um navio é única para cada indivíduo. Por mais que se tente falar sobre as diversas sensações, é difícil expressar a sensação de estar em alto mar. A chegada a cada porto de escala é um momento especial da viagem marítima, pois se descobre a silhueta da paisagem: as montanhas, serras, baias e as formas das cidades, que vão se descortinando à medida que o navio se aproxima da costa.

Esta combinação de paisagem costeira (litorânea) e de paisagem oceânica pode proporcionar diferentes sensações aos viajantes. A paisagem num cruzeiro difere daquela paisagem estática encontrada, por exemplo, nos resorts turísticos, pois a chegada em diferentes portos provoca imaginários mutantes .O contato íntimo e freqüente com o oceano confere, portanto, às viagens marítimas características próprias não encontradas em nenhum outro tipo de viagem.

Embora a paisagem oceânica esteja sempre presente num cruzeiro marítimo, pois faz parte de seu entorno, sua percepção pode ser subjetiva, e neste tipo de viagem embora o homem esteja intimamente em contato com a natureza, muitas vezes não a percebe. Trazemos então para uma reflexão as idéias de Tuan (1980, p.109-110). O turista moderno é propenso a colecionar imagens em sua câmera fotográfica, provando para ele mesmo e para as pessoas de seu relacionamento que esteve realmente no local visitado, esquecendo-se muitas vezes de observar e se integrar com a natureza. Concordamos com o autor quando afirma que o envolvimento do homem tecnológico com a natureza é mais recreacional do que vocacional. Percebemos isto nos cruzeiros marítimos. Os turistas buscam o cruzeiro mais para se divertirem a bordo de um "resort flutuante" do que para observarem e se integrarem à natureza. Deixam de perceber pequenos detalhes ou mesmo cenários simples, perdendo oportunidades de integração com o meio natural.

Ainda baseando-nos em Tuan, concluímos sobre o turismo possuir uma utilidade social e beneficiar a economia, porém muitas vezes deixa de integrar o homem à natureza. Num cruzeiro marítimo não é diferente, porém, assim como não podemos generalizar, o navio pode aproximar ou separar o homem da natureza. Dependerá da percepção e envolvimento de cada indivíduo e de suas necessidades enquanto estiver em viagem. Os diferentes cenários que se apresentam num cruzeiro marítimo podem se tornar um diferencial, pois combinam céu, sol e mar, enquanto o navio está em navegação, às silhuetas de ilhas, cidades e montanhas, quando o navio se aproxima ou se distancia da costa. Um cruzeiro marítimo oferece a oportunidade única do viajante mudar seu foco de paisagem e vislumbrar o continente a partir do mar. 


\section{O ritmo do lazer nos cruzeiros marítimos}

Quando avistamos um navio ao longe, em alto mar, é possível perceber a lentidão de seu deslocamento, pois o ritmo de navegação em nada pode ser comparado ao de outros meios de transportes modernos. A velocidade de um navio de cruzeiros pode chegar a 30 nós, ${ }^{4}$ aproximadamente 60 quilômetros por hora, ritmo lento se compararmos a um automóvel em deslocamento por rodovias (100 a $150 \mathrm{~km} / \mathrm{hora}$ ), ou a um avião riscando o céu (acima de 600 $\mathrm{Km} / \mathrm{h}$ ), ou mesmo a um trem rápido cruzando paisagens (acima de $300 \mathrm{~km} / \mathrm{hora}$ ). Uma viagem de lazer por mar pode favorecer a diminuição do ritmo da vida moderna e a contemplação da natureza.

A escolha de uma viagem por navio transformar-se numa oportunidade para um envolvimento mais suave com a natureza. Podemos literalmente dizer que a bordo de um navio é possível ver a vida passar. Ao pensarmos neste navio como um complexo de lazer, a cadência da vida pode mudar completamente, pois o espaço confinado ganha um ritmo frenético com todas as opções de lazer, entretenimento e gastronomia oferecidos a bordo.

A versão moderna dos cruzeiros marítimos surgiu entre o final dos anos 1970 e início dos anos 1980. É neste período que desponta, então, o novo conceito para os cruzeiros marítimos, cujo principal objetivo era entreter o viajante durante a sua permanência a bordo. Novos elementos foram introduzidos a partir de então e esta se tornou uma modalidade de viagem para “curtir” intensamente cada momento, oferecendo uma diversidade de opções de lazer e entretenimento, sempre desenvolvidas e realizadas com a supervisão de profissionais. As áreas internas dos navios foram ampliadas para contemplar as diversas atividades sociais e o convívio entre os passageiros.

Atualmente os navios de lazer utilizam todos os seus espaços internos e externos para suprir as necessidades de um público heterogêneo que visa maximizar sua experiência a bordo. Dentre os espaços e atividades de lazer ao ar livre (outdoor) é possível usufruir de quadras poliesportivas, complexo de piscinas para públicos adulto e infantil, pista para caminhadas e ainda, plataforma para prática de esportes aquáticos ${ }^{5}$. Algumas companhias inovaram e criaram mini-quadras de golfe, paredes de escalada e cinema ao ar livre ${ }^{6}$. A mais nova área de lazer criada por uma companhia marítima é a piscina com ondas, que possibilita a prática de

\footnotetext{
${ }^{4}$ Velocidade do navio Queen Mary 2, considerado um dos maiores navios do mundo na atualidade. Um nó equivale a 1,852 quilômetros.

${ }^{5}$ Oferecida somente em alguns navios de estrutura menor, semelhante a um iate, cuja plataforma é retrátil e possibilita o uso de equipamentos para snorkel, windsurf, entre outros.

${ }^{6}$ Disponível em alguns navios da companhia Princess Cruises
} 
surf a bordo. ${ }^{7}$ As atividades realizadas por profissionais da área de lazer ou de educação física incluem ainda jogos de entretenimento, dança, torneios, gincanas, entre outros. Também para entreter os passageiros, a maioria das companhias marítimas inclui música no deck, com bandas, trios, cantores e bailarinos.

Quanto aos espaços e atividades indoor, podemos destacar, dentre outros, a academia de ginástica, o spa, o teatro, o cassino, os bares e a boate, disponíveis na maioria dos navios. Alguns navios também inovaram nos espaços internos, criando alguns inusitados, como a pista de patinação no gelo e ringue profissional de boxe, disponíveis em alguns navios da companhia Royal Caribbean Cruises, ou mesmo um planetário, disponível no Queen Mary 2, da Cunard.

Para aumentar a oferta de lazer, algumas companhias marítimas criaram cruzeiros temáticos. Podemos citar como exemplos o cruzeiro Fitness e o cruzeiro do Bem Estar, da companhia Costa Cruzeiros. No primeiro, o navio se transforma numa verdadeira academia de ginástica, com profissionais da área de educação física planejando e coordenando todas as atividades. No segundo exemplo, o navio torna-se um centro esotérico e coloca à disposição dos passageiros profissionais das áreas da saúde, beleza, educação física, etc.

Os mais recentes temas desenvolvidos em navios na última temporada da costa brasileira foram o “Cruzeiro do Pânico”, organizado pela Island Cruise para atrair aqueles indivíduos que se identificam com o programa Pânico na TV e, os cruzeiros culturais, criados pela CVC para atrair admiradores de alguns artistas brasileiros famosos.

Além do ambiente de bordo, um cruzeiro marítimo apresenta ainda ao turista a oportunidade de visitar diferentes cidades, os chamados portos de escala, quando então poderá conhecer e interagir com povos de culturas diferentes. Isto transforma a experiência de um cruzeiro mais rica se pensarmos que o turista pode ser o intermediário entre estas culturas, levando informações dos diferentes hábitos culturais para o seu ambiente rotineiro.

Essa oferta exacerbada de atividades de lazer criando muitas vezes um ritmo frenético de horários e uso de espaços vem de encontro ao discutido aqui anteriormente sobre a criação, pela sociedade industrial, do uso do tempo produtivo e seu significado.

Se tempo é dinheiro, não posso perdê-lo e tendo adquirido meu lazer com o dinheiro de meu trabalho, devo desenvolver o máximo de atividades para justificar a compra desse lazer.

\footnotetext{
${ }^{7}$ Opção oferecida, até o momento, somente a bordo do navio Freedom of the Seas, da companhia Royal Caribbean Cruises, recém-inaugurado.
} 
Nesse panorama, a realização de atividades e sua contabilidade irão se aproximar de uma prestação de contas ao prazer, onde o acúmulo de atividades representa um saldo positivo.

O caráter de fruição, contemplação, relaxamento e descanso, o qual se aproximaria de um clima de descontração, cedem espaço para uma lógica próxima do trabalho ${ }^{8}$, muitas vezes com cobranças de resultados, regras excessivas e controles exagerados se unindo à necessidade de "fazer algo" para justificar o alto empreendimento.

\section{O corpo em alto mar}

Na inclusão da questão do corpo em nosso trabalho, pensamos não só no bem-estar que o contato com a natureza causa ao homem, mas também as diversas sensações proporcionadas. Não mencionaremos aqui as propriedades medicinais que o sol e o mar desencadeiam, extremamente utilizadas no século $\mathrm{XIX}^{9}$, mas sim, como o indivíduo percebe o corpo neste ambiente.

Inicialmente devemos entender o ambiente de um cruzeiro marítimo. Durante o dia é possível desfrutar de muito sol e se refrescar na piscina. A brisa e a amplitude do mar ajudam a construir um ambiente propício para a exibição do corpo. Assim, os indivíduos aproveitam o dia num navio como se estivessem numa praia, circulando seus corpos seminus, com biquínis e sungas, esperando o corpo dourar ao sol do alto mar. Segundo Farias (2002, p.276), a cor bronzeada, o estar moreno, é sinônimo de beleza e saúde e é o mais alto grau de hierarquia das cores da praia. À noite, o corpo bronzeado é mostrado aos outros participantes do cruzeiro, durante as atividades sociais.

Freqüentemente são ouvidos comentários sobre a relação da cor morena da pele e aparência saudável com o cruzeiro marítimo. Há uma tendência de algumas companhias oferecerem tratamentos prolongados de beleza nos Spas a bordo. Para facilitar a exposição do corpo “natural” ao sol, algumas companhias marítimas possuem áreas restritas para a prática de topless $^{10}$, onde as passageiras mais liberais podem aproveitar o ambiente confinado e se livrar da parte superior de seus biquínis. Visitando navios europeus atracados em portos brasileiros, tivemos a oportunidade de presenciar a prática de topless na área comum da piscina.

\footnotetext{
${ }^{8}$ No artigo “Sobre o Fim de Semana” Bruhns (2005) desenvolve como essa lógica do trabalho permeia a suposta descontração do fim de semana.

${ }^{9}$ Ver Corbin (1989), principalmente3 o capítulo “A nova harmonia do corpo e do mar”

${ }^{10}$ A companhia Carnival Cruise Lines é uma das companhias que possui estas áreas específicas.
} 
Quando falamos do corpo, não podemos minimizá-lo à simples estrutura de ossos, pele e músculos, mas devemos incluir todos os sentidos, pois estes não podem ser dissociados do corpo humano e através deles emoções e sentimentos participam da interpretação do mundo. A paisagem marítima contribui para uma maior percepção do corpo e dos sentidos. Lembrando Tuan (1980, p.285), somos um organismo biológico, um ser social e um indivíduo único e estamos biologicamente equipados para registrar um sem número de estímulos ambientais. O autor menciona como no mundo moderno o sentido mais favorecido é a visão, em detrimento da audição, tato e olfato. O olfato e o tato são os sentidos que mais requerem proximidade e ritmo lento para funcionar e despertar emoções.

Refletindo sobre a afirmação de Tuan, percebemos que os cruzeiros, enquanto atividade de lazer realizada em ambiente natural e num ritmo mais lento que as viagens tradicionais, podem representar a busca para o despertar de emoções, pois a audição é aguçada quando ouvimos o barulho do mar no deslocamento do navio; o tato é facilmente percebido, pois a brisa do mar e o vento tocam os corpos. O olfato também é privilegiado, pelo cheiro do mar dentre outros. Utilizaremos a idéia de Bruhns (2002) para comparar os cruzeiros marítimos a um exercício dos sentidos: "ver, ouvir, tocar, cheirar ou degustar sons, cores, superfícies, cheiros ou sabores, faz parte de um conjunto intenso onde a totalidade agora é representada pelo corpo como um todo, o qual ‘toca a natureza’ e é por ela tocada”.

A viagem marítima pode se constituir num exercício dos sentidos e percepções através da experiência sensível por ela provocada causando um modo de conhecimento relacionado a determinadas emoções, fundidas com os sentidos corporais, no contato com a natureza.

Esse aprendizado da experimentação, onde está presente certa sensibilização, revela um modo de conhecer especial, ou seja,o conhecimento do ambiente decodificado via informações do corpo. Evidentemente essa proposta relacionada ao corpo não é muito valorizada nos cruzeiros marítimos, perdendo espaço para a valorização de atividades envolvendo o corpo na sua visibilidade.

\section{Considerações Finais}

Os cruzeiros marítimos estão atualmente experimentando uma nova fase de crescimento. $\mathrm{O}$ Brasil começa a redescobrir esta modalidade de turismo e os brasileiros por sua vez, tornamse acostumados com os navios na costa durante a temporada de verão. 
O principal atrativo destas viagens são as infra-estruturas oferecidas, incluindo além do próprio transporte, a hospedagem, os alimentos e bebidas, as atividades de lazer e entretenimento e os diferentes destinos. Portanto, a fruição, a contemplação e o relaxamento deixam a desejar.

A experiência da viagem marítima é cercada por diferentes símbolos construídos no imaginário, envolvendo a fúria do mar, os deuses e modos de vida estranhos. Infelizmente nosso espaço neste artigo não possibilitou muito o desenvolvimento desse tema.

O homem contemporâneo tem um ritmo de vida acelerado e o ambiente de um cruzeiro pode ajudar nesta desaceleração, exercitando a lentidão. A viagem é realizada num ritmo mais lento e desta forma, a sensação de estar em contato com a natureza cria uma percepção diferente em cada viajante, aguçando todos os seus sentidos durante a viagem. Quando se está a bordo de um navio, o olhar ganha um novo foco, pois, o olhar do mar descobre cenários que o olhar para o mar, ou seja, a partir da praia, jamais oferecerá.

A preocupação com o corpo no último século foi centrada no exercício dos grandes músculos, tendões e articulações, preparando-o para certa agilidade e velocidade. A visibilidade do corpo (o que pode ser medido e quantificado) recebeu uma valoração diferenciada em relação aos seus aspectos não visíveis como as emoções (muito relacionadas aos sentidos) e os sentimentos; fruto da racionalidade de determinada ciência.

O cruzeiro marítimo poderia valorizar o refinamento de nossa sensibilidade exercitando mais nossos sentidos e sentimentos para resgatar a possibilidade de expressarmos de modo mais fluído nossas experiências pessoais. Deixamos escapar imagens e idéias as quais poderiam ser mais originais, a favor de chavões para expressar avaliações e julgamentos de nossas experiências.

Experiências efêmeras como esta talvez pudessem ser melhor interpretadas se nos preocupássemos mais com as informações obtidas através de nossos sentidos, as quais poderiam contribuir de forma mais íntima para uma interpretação mais envolvente do meio que nos cerca e onde estamos inseridos.

\section{Referências Bibliográficas}

BACHELARD, Gaston. 1997. A água e os sonhos: ensaio sobre a imaginação da matéria. São Paulo: Martins Fontes.

BAUDRILLARD, Jean. 1992. Da Sedução. $2^{\circ}$ ed. Campinas: Papirus. 
BRUHNS, Heloisa Turini. 2002. No ritmo da aventura: explorando sensações e emoções. In Turismo, lazer e natureza. São Paulo: Manole.

. 2002. De Grazia e o lazer como isenção de obrigações. In Lazer e Ciências Sociais: Diálogos pertinentes. São Paulo: Chronos.

DIEGUES, Antonio Carlos. 1998. Ilhas e mares: simbolismo e imaginário. São Paulo: Hucitec.

FARIAS, Patricia. 2002. Corpo e classificação de cor numa praia carioca. In: Goldenberg, Miriam (org). Nu e vestido-dez antropólogos revelam a cultura do corpo carioca. Rio de Janeiro: Record.

MAFFESOLI, Michel. 1998. O tempo das tribos. $2^{\circ}$ ed., Rio de Janeiro: Forense universitária.

RABAHY, Wilson e KADOTA, Décio. 2006. Caracterização da demanda das viagens de cruzeiros marítimos no Brasil. In Revista Turismo em Números. Ano 5 - Edição n 53/2006. Caderno de Estatísticas.

SANTOS, Laymert Garcia dos. 2000. Consumindo o futuro. In: Caderno Mais!, Jornal Folha de São Paulo, 27/02/2000

TUAN, Yi-Fu. 1980. Topofilia - Um estudo da percepção, atitudes e valores do meio ambiente. São Paulo: Difel.

Recebido em: 30/07/2006 (1 ${ }^{\text {a }}$ versão) $08 / 03 / 2007$ ( $2^{\mathrm{a}}$ versão)

Aprovado em: 8/03/2007 